\title{
Prospective Study of Medication Adherence Pattern in Chronic Obstructive Pulmonary Disease and Asthma Patient's in Tertiary Care teaching Hospital
}

\author{
Ajay R Fugate ${ }^{1,3^{*}}$, A M Kadam ${ }^{2,3}$ and M S Ganachari ${ }^{3}$ \\ 1Department of Pharmaceutics, Govindrao Nikam College of Pharmacy, Sawarde, Chiplun, Maharashtra, India. \\ ${ }^{2}$ Ashokrao Mane College of Pharmacy, Peth Vadgaon, Kolhapur, 416112, Maharashtra, India. \\ ${ }^{3}$ Department of Pharmacy Practice, KLES's College of Pharmacy, Belgaum, 590010, Karnataka, India.
}

\begin{abstract}
Lack of patient compliance with prescribed regimen is an important fascinating problem in medical care, especially in patients suffering from chronic illnesses. Asthma and Chronic Obstructive Pulmonary Disease (COPD) are the two main chronic lung disorders which are particularly vulnerable for medication non-adherence problem. Aim of the study was to assess medication adherence by self-report method to understand various determinants of medication non-adherence, and to enhance adherence using the strategies of counseling, education, and interviewing the patient. The prospective study was conducted for period of six months, assessed medication and inhaler adherence by administering Morisky self-reported questionnaires and inhaler technique were assessed by the standard checklist. Also reported the reasons for non-adherence. The study shows there was statistically significant increase in medication $(P<0.001)$ and inhaler adherence score $(P<0.001)$ and inhaler technique score $(\mathrm{P}<0.001)$ from baseline after pharmacist counseling regarding disease and medication. Comparison between various demographic factors like age, gender, diagnosis, duration of disease, and education status showed equal impact of pharmacist counseling on improvement of overall medication adherence score. Overall medication adherence and inhaler technique improvement was found to be statistically significant in asthma and COPD patients after counseling by pharmacist. The major reasons for medication non-compliance were felt better and stopped, high cost of medication, forgetfulness and lack of access to drug store/hospital.
\end{abstract}

Key words: Asthma, COPD, Clinical pharmacist, Medication Adherence, Patient education.

\section{INTRODUCTION}

Medication adherence is one of the most important factors that determine therapeutic outcomes, especially in patients suffering from chronic illnesses. Whatever the efficacy of a drug, it cannot act unless the patient takes it. Low medication adherence has assumed importance as it seriously undermines the benefits of current medical care and imposes a significant financial burden on individual patients and the healthcare system as a whole.

Patient adherence can be defined as the extent to which a person's behavior coincides with health related advice and ability of the patient to attend clinic appointments as scheduled, take medications as prescribed, make possible life style changes and complete recommended investigations. ${ }^{1}$ Adherence to pharmacologic therapy has been reported to be low among patients with Chronic Obstructive Pulmonary Disease (COPD) and related to poor prognosis. Currently, little is known about the extent and management of adherence problems among patients with chronic bronchitis and emphysema. ${ }^{2}$ In chronic airflow obstruction different classes of drugs are often used in combination, and in regimens requiring multiple daily doses of each agent. The resulting dosage schedules are often extremely complex. It has been considered that complex treatment regimens should result in poor compliance. ${ }^{3}$ Asthma is a common and chronic condition character-
Submitted date :25/03/2015 Accepted date :06/06/2015

DOI: 10.5530/ijopp.8.2.6

Address for correspondence: Mr. Ajay R Fugate,

Department of Pharmaceutics, Govindrao Nikam College of Pharmacy, Sawarde, Chiplun Maharashtra, India.

Phone no:91-9403685584

E-mail:fugatear@gmail.com

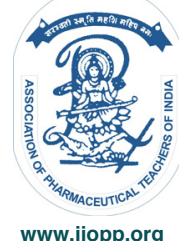

www.ijopp.org 
ized by reversible airflow obstruction, airway inflammation and increased airway responsiveness to a variety of stimuli. Poor asthma control is responsible for a large proportion of the total cost of the disease, and both indirect and direct cost would decrease if control were improved. Poor compliance with prescribed therapy leads to increased morbidity and mortality. Studies have reported that $50 \%$ of patients with chronic disease including asthma ${ }^{2}$ do not use their medication or do not use it as prescribed. ${ }^{4}$ There is a marked variation in therapeutic compliance from complete adherence to less than a quarter of the prescribed doses of inhaled prophylactic agents in asthma. ${ }^{5}$

In a recent document, the World Health Organization recognized lack of adherence as a major problem in management of chronic disease and concluded that improving adherence would have a more beneficial impact on health outcome than improving specific treatments. ${ }^{6}$ It is an acceptable fact of modern medicine that despite tremendous advances in diagnostic accuracy, if patients fail to take recommended treatment the expenses and efforts involved are virtually wasted. $^{7}$

\section{MATERIAL AND METHODS}

The study was approved by the Institutional Ethics Committee of JNMC of the KLES College of Pharmacy. Study was carried out at OPD of Respiratory medicine among patients diagnosed to have asthma and COPD at KLES hospital and medical research center. It was a prospective type of study initiated from June to December, in which patients receiving treatment for asthma and COPD were included in the study. Inclusion criteria were, patients of either sex with $\geq 18$ years of age and have been diagnosed with COPD or Asthma, patients have been receiving drugs for COPD or Asthma from at least last 3 months, and patients willing to participate. The exclusion criteria were patients having other medical or psychiatric co morbidities and first visit for asthma or COPD. Demographic data was obtained from all the patients.

A total of 54 patients were enrolled in to the study on their visit to the hospital and study duration was 6 months. Medication Adherence, Inhaler technique assessment and Counseling sessions upon enrollment of patients were evaluated for medication adherence by using Morisky's adhérence questionnaires, Standard checklist for correct inhaler use, and reasons to stop \} miss medications. Depending upon patient's adherence score, patients were counseled on medication, their disease, correct inhaler use and importance of medication adherence by the pharmacist.

\section{Patient Counseling}

At the outpatient department of respiratory medicines, counseling was performed in a separate chamber to ensure privacy. Counseling session was designed so that all patients were counseled according to their individual understanding and attitude towards their disease and medication. Pharmacist explained about their disease, correct medication $\backslash$ inhaler use, role of medications, importance of adherence, preventive measures etc. Patient education was done by using charts, posters, patient information leaflets and demonstration on correct inhaler use in their own language (Kannada, Marathi etc) by pharmacist.

\section{Follow up visits}

All patients were followed up for two subsequent appointments, with an interval of one month, to reassess their adherence score and correct inhaler technique.

\section{Statistical analysis}

Statistical analysis was carried out to study the significant difference between the follow ups in adherence level and correct inhaler technique. The statistical analysis was done using Mann-Whitney $U$ test, ANOVA test and McNemar test. The results section mentions the application of Mann Whitney $U$ test for assessing adherence. However no where the use of ANOVA and McNemar test has been discussed to assess the results. The researchers need to explain this.

\section{Ethical clearance}

The study was approved by Jawaharlal Nehru Medical College Institutional Ethics Committee on Human Subject Research, Nehrunagar, Belgaum and issued ethical clearance certificate.

\section{RESULTS AND DISCUSSION}

\section{Details of patients enrolled into the study}

During the six month study period, total of 60 (asthma and COPD) patients were enrolled as per our inclusion and exclusion criteria. Total of 54 (asthma and COPD) patients completed the study; the remaining six patients did not turn for the follow up due to unknown reasons. Demographic characteristics of enrolled Asthma and COPD patients are shown in Table 1.

\section{Patient Medication History}

Majority of patients were using inhaled $\beta 2$ agonists, inhaled corticosteroids, oral Methyl Xanthines and inhaled anti-cholinergics as a single or combination 
Table 1: Demographic characteristics of enrolled Asthma and COPD patients

\begin{tabular}{|c|c|c|c|c|}
\hline \multirow{2}{*}{ Basic Variable } & \multicolumn{2}{|c|}{ Asthma } & \multicolumn{2}{|c|}{ COPD } \\
\hline & Male & Female & Male & Female \\
\hline $\begin{array}{l}\text { No. of Patients } \\
\text { Enrolled in Study }\end{array}$ & 20 & 14 & 23 & 03 \\
\hline $\begin{array}{l}\text { No. of Patients } \\
\text { Completed Study }\end{array}$ & 19 & 13 & 20 & 02 \\
\hline $\begin{array}{l}\text { Percentage } \\
\text { of Patients } \\
\text { Completed Study }\end{array}$ & $59.37 \%$ & $40.62 \%$ & 90.90 & $9.09 \%$ \\
\hline \multicolumn{5}{|l|}{ Age in years } \\
\hline $18-45$ & \multicolumn{4}{|c|}{$21(38.88 \%)$} \\
\hline $46-64$ & \multicolumn{4}{|c|}{$20(37.03 \%)$} \\
\hline$\geq 65$ & \multicolumn{4}{|c|}{$13(24.07 \%)$} \\
\hline \multicolumn{5}{|c|}{ Educational Background } \\
\hline Literate & \multicolumn{4}{|c|}{$24(44.42 \%)$} \\
\hline Illiterate & \multicolumn{4}{|c|}{$30(55.55 \%)$} \\
\hline \multicolumn{5}{|c|}{ Duration of Disease (Years) } \\
\hline$<01$ & \multicolumn{4}{|c|}{$06(11.11 \%)$} \\
\hline 01 to 10 & \multicolumn{4}{|c|}{$36(66.66 \%)$} \\
\hline$\geq 11$ & \multicolumn{4}{|c|}{$12(22.22 \%)$} \\
\hline
\end{tabular}

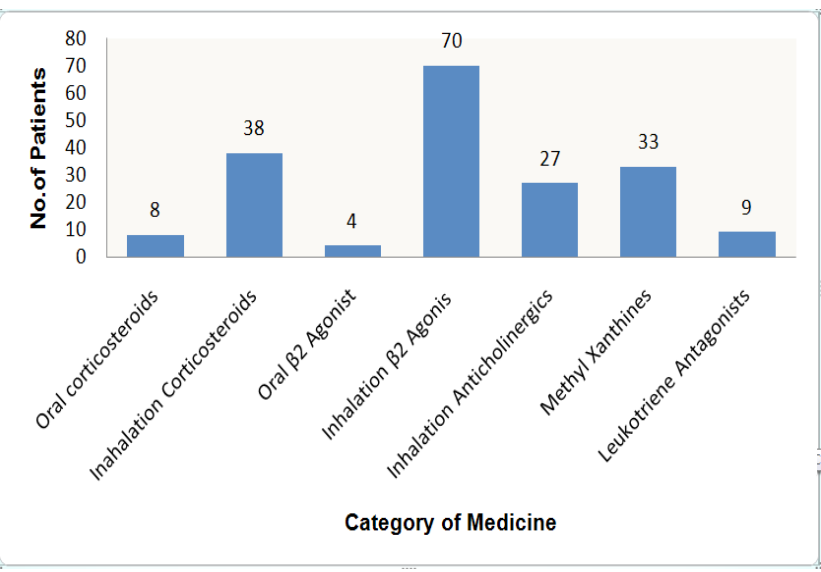

Figure 1: Medications used by the Patients

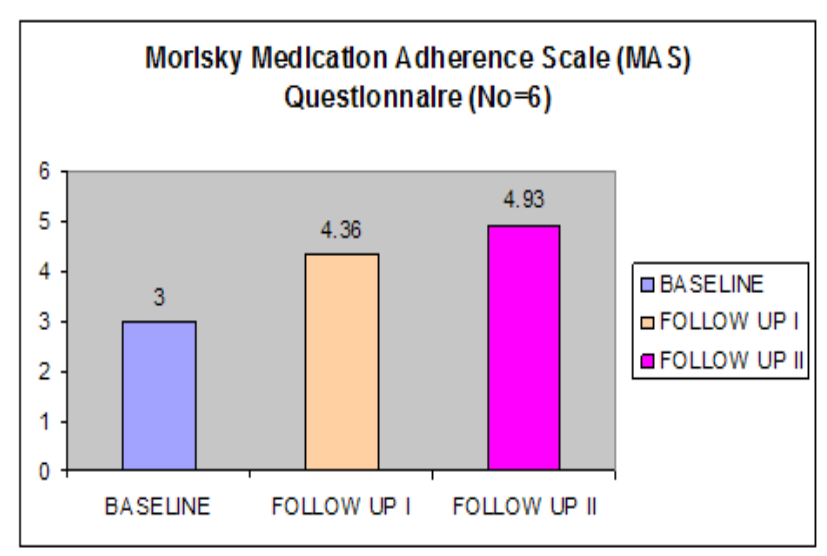

Figure 2: Baseline adherence score to first follow up score and second follow up Morisky Medication Adherence Scale (MAS) Score therapy. Other drugs used were oral corticosteroids and oral $\beta 2$ agonists (Figure 1).

\section{Assessment of medication adherence}

Morisky Medication Adherence Scale (MAS) Score and Morisky Inhaler Adherence Scale (IAS)

All the 54 participants of the study were initially provided MAS and IAS questionnaires at the time of enrollment and subsequent follow up, oral medication adherence score and inhaler adherence was evaluated at baseline, first and second follow up. The baseline data was compared with first and second follow up using Mann-Whitney U test.
Baseline with first follow up has revealed a mean increase in medication as well as inhaler adherence level of $1.477(\mathrm{P}<0.001), 1.404(\mathrm{P}<0.001)$ respectively, which is statistically significant.

Baselines to second follow up show a mean increase of $2.023(\mathrm{P}<0.001), 2.000(\mathrm{P}<0.001)$ respectively, which is significant it is shown in Table 2 and Figure 2, 3.

\section{Asthma}

Baseline score with first follow up score in asthma patients has revealed a mean increase in medication adherence level of 1.406 with $\mathrm{P}<0.001$ which is statistically significant. Baselines to second follow up show a 


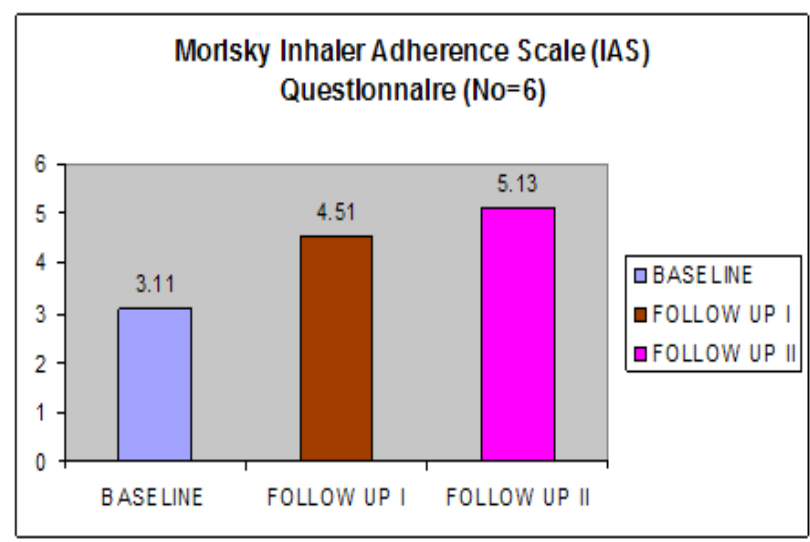

Figure 3: Baseline adherence score to first follow up score and second follow up Morisky Inhaler Adherence Scale

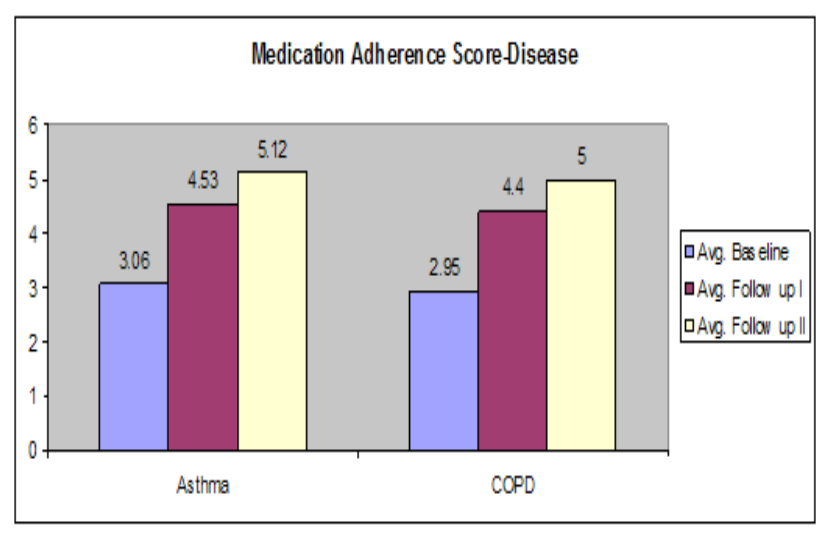

Figure 4: Medication adherence score Disease

\begin{tabular}{|c|c|c|c|c|c|}
\hline \multicolumn{3}{|c|}{ Medication Adherence Scale } & \multicolumn{3}{|c|}{ Inhalation Adherence Score } \\
\hline & & P Value & & & P Value \\
\hline Baseline & 3 & & Baseline & 3.11 & \\
\hline Ist Follow Up & 4.36 & $P<0.001$ & Ist Follow Up & 4.51 & $P<0.001$ \\
\hline II nd $_{\text {follow up }}$ & 4.93 & $P<0.001$ & IInd Follow up & 5.13 & $P<0.001$ \\
\hline
\end{tabular}

Table 3: Medication adherence scores in asthma patients

\begin{tabular}{cccccccc}
$\begin{array}{c}\text { Average } \\
\text { Baseline }\end{array}$ & $\begin{array}{c}\text { Average } \\
\text { Follow up Ist }\end{array}$ & Mean SD & P-value & $\begin{array}{c}\text { Average } \\
\text { Baseline }\end{array}$ & $\begin{array}{c}\text { Average } \\
\text { Follow up IInd }\end{array}$ & Mean SD & P-value \\
\hline 3.06 & 4.53 & $1.406 \pm 1.012$ & $P<0.001$ & 3.06 & 5.12 & $2.000 \pm 0.984$ & $P<0.001$ \\
\hline
\end{tabular}

Table 4: Medication adherence scores in COPD patients

\begin{tabular}{cccccccc}
$\begin{array}{c}\text { Average } \\
\text { Baseline }\end{array}$ & $\begin{array}{c}\text { Average } \\
\text { Follow up | }\end{array}$ & Mean SD & P-value & $\begin{array}{c}\text { Average } \\
\text { Baseline }\end{array}$ & $\begin{array}{c}\text { Average } \\
\text { Follow up IId }\end{array}$ & Mean SD & P-value \\
\hline 2.95 & 4.40 & $1.476 \pm 0.980$ & $P<0.001$ & 2.95 & 5.00 & $2.095 \pm 1.044$ & $P<0.001$ \\
\hline
\end{tabular}

mean increase of 2.000 with $\mathrm{P}<0.001$ which is significant. as shown in Table 3.

\section{COPD}

Baseline score with first follow up score in asthma patients has revealed a mean increase in medication adherence level of 1.476 with $\mathrm{P}<0.001$ which is statistically significant. Baselines to second follow up show a mean increase of 2.095 with $\mathrm{P}<0.001$ which is significant. As shown in Table 4. compartive medication adherence score shown on Figure 4.

Effect of pharmacist counseling was compared with improvement of medication adherence score between asthma and COPD patients. It shows there is no significant difference between asthma and COPD adherence score at first follow up $(\mathrm{P}=0.357)$ and at second follow $\operatorname{up}(\mathrm{P}=0.330)$.

\section{Self-Reported Reasons to Stop/Miss Medications}

During the time of baseline assessment we asked the reasons to stop/miss medications by the patients. Following were the reasons as shown in Table 5.

\section{DISCUSSION}

This study was designed to assess the effectiveness of patient counseling by pharmacist on asthma and COPD patient medication adherence and inhaler technique.

In our study, following individualized counseling that addressed individual barriers to not using their medication and inhalers, patients had a significant improvement in self-reported compliance to the medications $(\mathrm{P}<0.001)$ and inhalers $(\mathrm{P}<0.001)$. These results show the need for pharmacist-mediated counseling regarding the disease and medications in asthma and COPD 


\begin{tabular}{lcc}
\hline \multicolumn{1}{c}{ Table 5: Self-reported Reasons to Stop/Miss Medications } & \\
\hline High cost of medication & $\begin{array}{c}\text { No. of Patients } \\
(\mathbf{n}=\mathbf{5 4})\end{array}$ & Percentage (\%) \\
\hline Lack of access to hospital/drug store & 23 & $42.59 \%$ \\
Fear of side effects & 17 & $31.48 \%$ \\
Felt better and stopped & 08 & $14.81 \%$ \\
Non Beneficial & 35 & $64.81 \%$ \\
Forgotten/Occupation related problems & 05 & $9.25 \%$ \\
Lack of family support/Motivation & 30 & $55.55 \%$ \\
Fear of becoming dependent on treatment & 09 & $16.66 \%$ \\
\hline
\end{tabular}

patients. Comparison amongst various factors like age, gender, type and duration of disease, showed equal impact on improvement adherence level to medication and inhaler. Providing these data would improve the standard of the article significantly. Various studies. ${ }^{8,9-12}$ conducted on medication adherence and inhaler techniques also showed similar findings.

The major reported reasons to stop/miss medication were felt better and stopped (64.81\%) because asthma and COPD has symptomatic treatment, so whenever feel better they stop the medicine, forgetfulness $(55.55 \%)$, expensive $(42.59 \%)$ and lack of access to drug store/hospital (31.48\%). Other minor reasons were lack of family support/Motivation, fear of side effects, feel non beneficial. The same reasons were reported in previous studies. Hence we focused on reasons which has greater impact on adherence level and can be minimized by pharmacist counseling. Need to mention these reasons. Many studies report same reasons to stop/miss medication. ${ }^{7,13-15}$ Asthma and COPD are chronic disorders, hence medication adherence is poor in chronic disorders due to depression, cost of medicines, ran out of medicines etc..$^{2-8,16}$ In India, poor people don't have health or medical insurance as like in western countries. So we can emphasize on these insurance policies by individual or by government policies to give economic support to such patients. In rural India, we still lack access to healthcare or drug store. In a process of civilization in future, we can expect good access to healthcare or drug store in rural or remote part of India.

\section{REFERENCES}

1. Mahesh PA, Parthasarathi G, Parthasarathi G, Hansen KN, Nahata MC. Medication Adherence, Textbook of Clinical Pharmacy Practice, Essential concepts and skills. Orient Longman Publications Pvt. Ltd; 2004. 54-71.

2. Dolce JJ, Crisp C, Manzella B, Richard MJ, Hardin M, Bailey CW. Medication Adherence Pattern in chronic obstructive Pulmonary Disease. CHEST 1999; 99(4): 837-41.

3. James PNE, Anderson JB, Prior JG, White JP, Henry JA, Cochrane GM. Pattern of drug taking in patients with chronic airflow obstruction. Postgraduate Medical Journal 1985; 61(711): 7-10.
Further structured research should be done to address above problems related to poor medication adherence.

\section{CONCLUSION}

Overall medication adherence and inhaler technique improvement was found to be statistically significant in asthma and COPD patients after counseling by pharmacist. Medication adherence assessment by self-reporting method was found to be good and this method is liable to go unreliable since it depends fully on the patients report. The major reasons for medication non-compliance were felt better and stopped, high cost of medication, forgetfulness and lack of access to drug store/ hospital. Other reasons were fear of side effects, lack of family support/motivation, fear of becoming dependent on treatment and non-beneficial treatment. Patients counseling may be effective to resolve these problems associated with medication non-adherence except high cost of medications and lack of access to medications/ hospital which require further strategies. Future studies should include newer strategies to assess the adherence level and long term and large population studies.

\section{ACKNOWLEDGEMENTS}

We wish to acknowledge Principal, KLES College of pharmacy, Belgaum and Director, KLE's Prabhakar Kore Hospital and Medical Research Centre, Belgaum, HOD, Department of Respiratory Medicine for giving an opportunity to carry out this project and the support provided in the successful completion of this study.

4. Lindberg M, Ekstorm T, Moller M, Ahlner J. Asthma care and factors affecting medication compliance: The patient's point of view. Int J Qual Health Care. 2001; 13(5): 375-83.

5. Yeung M, Connor SA, Parry DT, Cochrane GM. Compliance with prescribed drug therapy in asthma. Respir Med. 1994; 88(1): 33-5.

6. Baiardini I, Braido F, Giardini A, Majani G, Cacciola C, Rogaku A, et al. Adherence to Treatment: Assessment of an Unmet Need in Asthma. J Investig Allergol clinical Immunol. 2006; 16(4): 218-23.

Indian Journal of Pharmacy Practice, Vol 8, Issue 2, Apr-Jun, 2015 
7. Chotai NP, Patel HV, Patel VA, Patel BG. Patients Non-Compliance-A Case Study. The Indian Journal of Hospital Pharmacy; 2006. 185-90.

8. Prabhakaran L, Lim G, Abisheganaden J, Chee CBE, Choo YM. Impact of an asthmaeducation programme on patient's knowledge, inhaler technique and compliance to treatment. Singapore Med J. 2006; 47(3): 225-31.

9. Cochrane MG, Bala MV, Downs KE, Mauskopf J, Ben-Joseph RH. Inhaledcorticosteroids for Asthma Thearapy: Patient Compliance, Devices and Inhalation Technique. CHEST 2000; 117(2): 542-50.

10. Mangiapane S, Schulz M, Muhlig S, Ihle P, Schubert I, Waldmann HC. Community Pharmacy-Based Pharmaceutical Care for Asthma Patients. Ann Pharmacother. 2005; 39(11): 1817-22.

11. Schulz M, Verheyen F, Muhlig S, Muller JM, Muhlbauer, Knop-Schneickert $\mathrm{E}$, et al. Pharmaceutical care services for asthma patients: A controlled intervention study. J Clin Pharmacol. 2001; 41(6): 668-76.

12. Wilson SR, Scamagas P, German DF, Hughes GW, Lulla S, Coss S, et al. A controlled trial of two forms of self-management education for adults with asthma. Am J Med. 1993; 94(6): 564-76.
13. George J, Kong DC, Thoman R, Stewart K. Factors associated with medication nonadherence in patients with COPD. CHEST 2005; 128(5): 3198-204.

14. Piette JD, Heisler M, Wagner TH. Cost-Related Medication Underuse: Do Patients With Chronic Illness Tell Their Doctors?. Arch Intern Med. 2004; 164(16): 1749-55.

15. Bender BG. Overcoming barriers to non-adherence in asthma treatment. J Allerg Clin Immunol. 2002; 109(6): 554-9.

16. Alam K, Palaian.S, Shankar RP, Bista D, Mishra P, Prabhu MM. Role of pharmacist in counseling asthma patients. Pharma Times 2007; 39(6): 13-8.

17. Sudhakar BL, Nagvi BG. The role of pharmacist in patient medication adherence. Indian Journal of Hospital Pharmacy 2006 Sep-October; 1747.

18. Sivasankaran P, Mallayasamy S, Nanjundiah A, Bhojraj S. Assessment of impact of medication counseling on patients medication knowledge and compliance in an outpatient clinic in South India. Patient Educ Counsel. 2003; 2137(1): 1-6. 